\title{
KEANEKARAGAMAN SEMUT (Famili Formicidae) PADA LAHAN GAMBUT DI LINGKUNGAN GEDUNG BARU FAKULTAS KEHUTANAN UNIVERSITAS TANJUNGPURA PONTIANAK
}

\author{
Diversity of Ant (Famili Formicidae) on Peatland at The New Building of The Forestry Faculty Of \\ Tanjungpura University in Pontianak
}

\author{
Nandini Rosa, Iswan Dewantara, Hari Prayogo \\ Fakultas Kehutanan, Universitas Tanjung Pura, Jalan Imam Bonjol Pontianak 78124 \\ Email: rosanandini@gmail.com
}

\begin{abstract}
Ants have an important role in an ecosystem such as seed spreaders, pollinators, decomposers, and soil growers. Ants can live on peatlands that have acidic $\mathrm{pH}$. The new building of the Faculty of Forestry is an area of peatland where there is one of the fauna, namely ants. The ants in the environment of the Faculty of Forestry's new biulding are unknown. The research aims to record the types of ants found on peatland in the environment of the new building of the Faculty of Forestry, Tanjungpura University. Takingthe samples of ants was done with sifting hand collecting and leaf litter sifting methods. This study found 4 subfamilies and 7 genera of ants. The subfamilies found were Subfamily Formicinae consisting of the genera Anoplolepis, Camponotus, Echinopla, and Polyrhachis, Subfamily Ponerinae consisting of Genus Diacamma; Subfamily Pseudomyrmecinae consisting of genus Tetraponera; and Subfamily Myrmicinae consisting of the Crematogaster Genus. Diversity index has a value of $H^{-}=1.44$ which indicates that the research location has moderate diversity. The overall index of species richness has a DMg value $=5.58$ indicating the wealth of ant species is in the high category. Evenness index with a value of 0.73 , evenness of ant species is quite even.
\end{abstract}

Keywords: Diversity of ants, Faculty of Forestry, Family Formicidae, Peatlands

\section{PENDAHULUAN}

Lahan gambut merupakan salah satu jenis lahan basah yang terbentuk oleh adanya timbunan reruntuhan vegetasi yang mengalami dekomposisi kurang sempurna. Wood (1995) menyatakan pada lahan gambut terdapat makrofauna tanah yang dibagi berdasarkan ukuran tubuhnya, yaitu mikrofauna (berukuran < 100 mikron), mesofauna (berukuran 100 mikron-2 mm) dan makrofauna tanah (berukuran 2-20 mm) salah satunya semut.
Semut adalah suatu kelompok yang sangat umum dan menyebar luas, sehingga mudah dikenali bagi semua orang. Wang et al. (2000) mengatakan semut merupakan jenis serangga yang memiliki populasi cukup stabil sepanjang musim dan tahun. Semut merupakan bioindikator perubahan lingkungan seperti kebakaran hutan, gangguan terhadap vegetasi, penebangan hutan, pertambangan, pembuangan limbah, dan faktor penggunaan lahan karena semut 
mempunyai toleransi terhadap perubahan lingkungan dan mampu merespon perubahan yang terjadi dalam ekosistem (Pecarevic et al., 2010). Griffith et al (2017) menyatakan peran semut dalam rantai makanan dan energi di dasar hutan tropis, semut yang kecil ternyata bertanggung jawab pada setengah proses dekomposisi sampah di dasar hutan. Sampah yang diuraikan oleh semut berupa tubuh mayat hewan, biji-bijian, dan buah busuk.

Kawasan gedung baru Fakultas kehutanan merupakan daerah lahan gambut yang terdapat makrofauna tanah yaitu semut. Semut ada yang hidupnya arboreal dan terrestrial. Semut yang ada di lingkungan gedung baru Fakultas Kehutanan belum diketahui jenisjenisnya, sehingga perlu dilakukan penelitian. Tujuan penelitian untuk mendata jenis-jenis semut yang ada pada lahan gambut di lingkungan Fakultas Kehutanan Gedung baru Universitas Tanjungpura serta memberikan informasi kepada masyarakat mengenai jenis- jenis semut dan pihak- pihak terkait sebagai perkembangan ilmu pengetahuan, serta data yang diperoleh dapat digunakan sebagai penelitian selanjutnya.

\section{METODE PENELITIAN}

Penelitian dilakukan di Fakultas Kehutanan Gedung baru Universitas Tanjungpura selama 2 minggu di lapangan mulai dari 11 Agustus 2018-24 Agustus 2018. Pengumpulan data yang diambil dalam penelitian adalah genus semut, jumlah individu semut yang terdapat dalam jalur pengamatan, suhu, udara, kelembaban udara, $\mathrm{pH}$ tanah dan vegetasi. Peletakan jalur pengamatan dilakukan secara sengaja (purposive sampling). Panjang masing-masing jalur $60 \mathrm{~m}$ dengan lebar ke kanan $1 \mathrm{~m}$ dan ke kiri $1 \mathrm{~m}$ sebanyak 3 jalur. Pengambilan sampling dengan metode hand collecting. Selain itu dilakukan juga pembuatan petak pengamatan dengan plot ukuran $1 \mathrm{~m} \mathrm{x} 1 \mathrm{~m}$, plot ini diletakan dalam jalur transek dengan interval $10 \mathrm{~m}$, pada plot ini digunakan metode Leaf Litter Siftting. Jalur 1 berada di sebelah kiri gedung Fakultas Kehutanan, jalur 2 berada di sebelah kanan antara gedung Fakultas Kehutanan dengan FKIP Universitas Tanjungpura, dan jalur 3 dibelakang kantin Fakultas Kehutanan. Identifikasi semut merujuk pada antweb dan jurnal penelitian semut.

\section{Analisis Data}

1. Indeks Keanekaragaman Jenis/ spesies

Indeks keanekaragaman spesies dihitung dengan menggunakan ShannonWiener Index (Ludwig \& Reynold 1988), yaitu:

$\overline{\mathrm{H}}=-\sum_{i=1}^{s}\left[\left(\frac{n i}{N}\right) \ln \left(\frac{n i}{N}\right)\right]$

Dimana:

$\overline{\mathrm{H}}=$ Indeks keanekaragaman ShannonWiener

$\mathrm{ni}=$ Jumlah individu setiap spesies

$\mathrm{N}=$ Jumlah individu seluruh spesies

$\mathrm{Ln}=$ Logaritma natural

Kategori indeks keanekaragaman jenis 
$\mathrm{H}^{\prime}<1=$ tingkat keanekaragaman rendah

H' 1-3 = tingkat keanekaragaman sedang $\mathrm{H}^{\prime}>3$ = tingkat keanekaragaman tinggi.

2. Indeks Kekayaan Jenis (DMg)

Mengetahui keanekaragaman jenis berdasarkan jumlah jenis pada suatu ekosistem. Indeks yang digunakan adalah Indeks kekayaan jenis Margalef (Magurran 1983):

$\operatorname{DMg}=\frac{(S-1)}{\ln N}$

Dimana:

$\mathrm{DMg}=$ Indeks Kekayaan Jenis Margalef $\mathrm{S}=$ Jumlah jenis yang ditemukan $\mathrm{N}=$ Jumlah individu seluruh jenis Kategori indeks kekayaan jenis $\mathrm{DMg}<2=$ menunjukan tingkat kekayaan yang rendah.

$2,5>\mathrm{DMg}>4=$ menunjukan tingkat kekayaan jenis yang sedang.

$\mathrm{DMg}>4=$ menunjukan tingkat kekayaan yang tinggi

3. Indeks Kemerataan Jenis (evenness/e)

Derajat kemerataan kelimpahan individu antara setiap spesies dapat ditentukan dengan indeks kemerataan spesies (Magurran 1983), yaitu:

$\mathrm{e}=\frac{H^{\prime}}{H \max }=\frac{\bar{H}}{\ln S}$

Dimana:
$\bar{H}=$ Indeks keanekaragaman spesies

$\mathrm{S}=$ jumlah keseluruhan spesies

Ln = Logaritma natural

$\bar{H}$ max akan terjadi apabila ditemukan dimana semua spesies adalah melimpah. Adapun, nilai E kisaran anatara adalah 0 dan 1 yang mana nilai 1 menggambarkan suatu keadaan di mana semua spesies melimpah (Fachrul, 2007).

\section{HASIL DAN PEMBAHASAN} Semut Yang Ditemukan Di Gedung Baru Fakultas Kehutanan

Hasil penelitian di sekitar gedung baru Fakultas Kehutanan Universitas Tanjungpura pada bulan Agustus 2018 yang diperoleh dengan menggunakan metode hand collecting dan leaf litter sifting ditemukan 4 Subfamili dan 7 Genus semut. Subfamili yang ditemukan yaitu Formicinae,

Ponerinae, Pseudomyrmecinae, dan Myrmicinae. Subfamili Formicinae terdiri atas genus Anoplolepis, Camponotus, Echinopla, dan Polyrhachis. Subfamili Ponerinae terdiri Genus Diacamma. Subfamili Pseudomyrmecinae terdiri atas Genus Tetraponera. Subfamili Myrmicinae terdiri atas Genus Crematogaster, subfamili, genus dan jumlah individu genus semut dapat dilihat pada Tabel 1. 
Tabel 1. Subfamili, Genus Dan Jumlah individu Genus Semut Yang Ditemukan Di Gedung Baru Fakultas Kehutanan Universitas Tanjungpura (Subfamily, Genus and Number of Ant Genus Individuals Found AtTh e New Building of The Forestry Faculty Of Tanjungpura University in Pontianak)

\begin{tabular}{llcc}
\hline \multirow{2}{*}{ Subfamili } & \multirow{2}{*}{ Genus } & \multicolumn{2}{c}{ Jumlah Individu } \\
\cline { 3 - 4 } Formicinae & Anoplolepis & Hand Collecting & Leaf Litter Sifting \\
& Camponotus & 55 & 34 \\
& Echinopla & 9 & 436 \\
Ponerinae & Polyrhachis & 537 & 146 \\
Pseudomyrmecinae & Diacamma & 0 & 280 \\
Myrmicinae & Tetraponera & 54 & 17 \\
& Crematogaster & 176 & 8 \\
\hline
\end{tabular}

Semut terbanyak yang ditemukan berasal dari Subfamili Formicinae mencapai empat genus, Subfamili yang lain hanya didapat satu genus. Genus Anoplolepis dari Subfamili Formicinae dan Genus Diacamma dari Subfamili Ponerinae tidak ditemukan di hand collecting dan hanya ditemukan di leaf litter sifting dari seluruh tiga jalur penelitian, ditemukannya di leaf litter sifting karena Genus Anoplolepis sebagai polinator berbagai fauna di serasah meskipun mereka dapat memangsa di kanopi, serta mencari makan di tanah sepanjang hari dan juga malam (Latumahina et al., 2014) dan Genus Diacamma merupakan Spesies yang banyak dijumpai aktif di serasah (Siriyah, 2016). Semut yang banyak didapat yaitu Polyrhachis dengan jumlah individu 537 di hand collecting dan di leaf litter sifting semut yang banyak didapat yaitu Genus Camponotus dengan 436 individu, Camponotus penyebarannya cukup luas di dunia, sarangnya sering ditemukan anatara kayu, akar tanaman, ranting maupum semak-semak atau pohon (Shattuck, 2001) (dalam Haneda \& Yuniar, 2015). Pada saat penelitian genus ini memang ditemukan di dekat akar pohon maupun berjalan di atas serasah. Genus semut yang didapat di hand collecting atau pada pohon dapat dilihat pada Tabel 2. 
JURNAL HUTAN LESTARI (2019)

Vol. 7 (2) : 723 - 732

Tabel 2. Jenis Pohon Dan Genus Semut Pada Hand Collecting (Tree Types and Ants Genus on Hand Collecting)

\begin{tabular}{cccc}
\hline Jalur & Jenis pohon & Genus Semut & Jumlah Individu \\
\hline 1 & Akasia & Polyrhachis & 107 \\
& & Tetraponera & 54 \\
& Crematogaster & 11 \\
& Mahang & Polyrhachis & 9 \\
& & Crematogaster & 3 \\
& Camponotus & 3 \\
& & Echinopla & 9 \\
& Angsana & Polyrhachis & 183 \\
& Rambutan & Camponotus & 7 \\
& & Crematogaster & 12 \\
& Karet & Polyrhachis & 25 \\
& Jambu & Camponotus & 30 \\
& Rambutan & Crematogaster & 130 \\
& Karet & Polyrhachis & 148 \\
& & Camponotus & 15 \\
& Akasia & Polyrhachis & 5 \\
& Jambu & Polyrhachis & 31 \\
& Polyrhachis & 5 \\
& & Crematogaster & 20 \\
\hline
\end{tabular}

Tabel 2 menunjukan dari keenam pohon ditemukan genus Polyrhachis yang mendominasi semua pohon di setiap jalur. Genus semut yang ditemukan pada pohon mahang ditemukan genus Camponotus, genus Polyrhachis, genus Crematogaster dan genus Echinopla. Semut yang didapat pada pohon mahang ternyata memiliki hubungan simbiosis. Federle et al, (1998) menyatakan sebagian besar pohon Macaranga merupakan mirmekofit (tumbuhan yang memiliki hubungan mutualisme dengan koloni semut) yang ditempati oleh semut dari kelompok spesies Crematogaster dari subgenus Decacrema. Macaranga memiliki batang yang berongga sehingga berfungsi sebagai ruang bersarang dan semut seringkali membuat sarang dibagian daun Macaranga, sebaliknya semut melindungi Macaranga dari serangan binatang herbivora.

Genus semut yang ditemukan pada pohon karet yaitu genus Polyrhachis dan Camponotus. Genus camponotus merupakan spesies yang dominan di hutan karet dan kebun karet. Banyaknya genus ini kemungkinan karena pohon karet menhasilkan zat senyawa tertentu (Haneda \& Yuniar, 2015). Pohon karet ternyata dapat menghasilkan madu yang berasal dari nektar bunga pohon karet (Evahelda $e t$ $a l, 2017)$, nektar ini yang membuat semut berada di pohon karet. Menurut Agussalim 
akasia dan karet yang dapat dijadikan genus Polyrhachis, Camponotus, dan Crematogaster sebagai tempat mencari makan dan bersimbiosis. Genus semut Camponotus dan echinopla semut ini banyak beraktivitas di serasah sehingga menggunakan metode leaf litter sifting berpeluang banyak didapat.

Indeks kekayaan jenis ditentukan oleh banyaknya jumlah spesies di dalam suatu komunitas dimana semakin banyak jenis yang teridentifikasi maka kekayaan spesiesnya pun tinggi (Magurran, 1988). Indeks keseluruhan kekayaan jenis memiliki nilai $\mathrm{DMg}=5,58$ menunjukan kekayaan jenis semut masuk kategori tinggi pada skala kategori tinggi pada skala kategori $\mathrm{DMg}>4$, hal ini dikarenakan genus semut yang ditemukan sebanyak 7 genus dari 4 subfamili dengan jumlah keseluruhan individu 1.861. Paling banyak ditemukan jumlah invidu semut pada serasah atau metode leaf litter sifting.

Kemerataan jenis digunakan mengetahui kemerataan setiap jenis dalam setiap komunitas. Semakin merata jumlah individu masing- masing spesies yang ditemukan semakin merata spesies tersebut (Magurran, 1988). Indeks kemerataan dengan nilai 0,74 , kemerataan genus semut tergolong cukup merata yaitu nilai E mendekati 1. Hal ini karena keanekaragaman genus semut seluruh jalur kategori sedang dan tiap jumlah individu banyak didapat, meskipun ada satu jenus dengan jumlah individu terendah.

\section{Faktor Lingkungan Terhadap Keberadaan Semut}

Andersen (2000) dalam (Haneda \& Yuniar, 2015) menyatakan keberadaan semut semut sangat terkait dengan kondisi habitat dan beberapa faktor utama yang mempengaruhi keberadaan semut, seperti suhu rendah, habitat yang kurang mendukung untuk membuat sarang, sumber makanan terbatas dan daerah jelajah yang kurang mendukung. Hasil pengamatan faktor lingkungan yang diamati dapat dilihat dalam Tabel 4. 
Tabel 4. Pengukuran Suhu Udara, Kelembaban Udara Dan pH Di Lingkungan Fakultas Kehutanan (Measurement Of Air Temperature, Air Humidity And pH In The Faculty Of Forestry Environment)

\begin{tabular}{|c|c|c|c|c|}
\hline Jalur & Genus Semut & $\begin{array}{c}\text { Suhu udara } \\
\left({ }^{\circ} \mathrm{C}\right)\end{array}$ & $\begin{array}{c}\text { Kelembaban } \\
\text { udara }(\%)\end{array}$ & pH \\
\hline 1 & $\begin{array}{c}\text { Anoplolepsis } \\
\text { Camponotus } \\
\text { Crematogaster } \\
\text { Echinopla } \\
\text { Polyrhachis } \\
\text { Tetraponera } \\
\text { Diacamma }\end{array}$ & 29,3 & 78 & 4.11 \\
\hline 2 & $\begin{array}{c}\text { Camponotus } \\
\text { Crematogaster } \\
\text { Polyrhachis } \\
\text { Diacamma } \\
\text { Echinopla } \\
\text { Tetraponera }\end{array}$ & 27,4 & 78,5 & 3.31 \\
\hline 3 & $\begin{array}{l}\text { Camponotus } \\
\text { Crematogaster } \\
\text { Polyrhachis } \\
\text { Diacmma } \\
\text { Echinopla } \\
\text { Tetraponera }\end{array}$ & 29,3 & 72 & 4.11 \\
\hline
\end{tabular}

Berdasarkan hasil pengukuran di lokasi penelitian rata-rata suhu udara antara $27,4^{\circ} \mathrm{C}$ $29,3^{\circ} \mathrm{C}$ dan kisaran kelembaban udara antara 72\%-78,5\%. Menurut Riyanto (2007) kisaran suhu udara antara $25^{\circ} \mathrm{C}$ sampai $32^{\circ} \mathrm{C}$ merupakan suhu optimal dan toleran bagi aktivitas semut di daerah tropis. Meilina et al. (2007) menyatakan penelitian yang dilakukan pada lahan gambut alami pada suhu $29^{\circ} \mathrm{C}$ ditemukan genus semut terbanyak yaitu, Acanthomyrmex, Camponotus, Crematogaster, Echinopla dan Tapinoma. Hasil genus semut pada lokasi penelitian dari ke tiga jalur selalu ditemukan genus Camponotus, Crematogaster dan Echinopla. Hal ini berarti suhu dilokasi penelitian optimal bagi semut sehingga semut mampu hidup pada lingkungan tersebut.
Pengukuran kelembaban udara pada lokasi menjukan kerapatan tajuk yang tinggi menyebabkan kelembaban udara tinggi, hal ini berkaitan dengan penyinaran matahari yang dipengaruhi oleh tajuk. Semut menyukai udara yang sejuk dan lembab dan tidak terlalu panas untuk aktivitas harian dan reroduksinya (Shattuck, 2000) dalam (Latumahina et al. 2015).

Keberadaan dan kepadatan semut sangat tergantung pada $\mathrm{pH}$ tanah dan mampu hidup pada rentang $\mathrm{pH}$ yang lebih tinggi dibandingkan cacing tanah (Maftu'ah et al, 2005). Semut biasanya dapat hidup pada tanah dengan $\mathrm{pH}$ asam maupun $\mathrm{pH}$ basa, sehingga dominasi semut sangat dipengaruhi oleh pH tanah. Pada lokasi penelitian memiliki pH tanah 3,31 dan 4,11, berarti 
genus semut yang ditemukan bisa bertahan di pH yang asam. Menurut Rahmawati (2004) fauna tanah ada yang senang hidup pada $\mathrm{pH}$ asam adapula yang senang pada $\mathrm{pH}$ basa tergantung pada jenisnya.

Pada pengambilan semut dengan metode leaf litter sifting serasah yang terdapat semut diambil sebanyak $\pm 10 \mathrm{~cm}$ dengan ayakan berukuran $40 \mathrm{~cm}$ x $40 \mathrm{~cm}$ dengan luas sel $1 \mathrm{~cm}$. Saat pengamatan banyak semut yang sedang mencari makan di bawah serasah, membawa biji-bijian atau pun remahan tanaman yang dapat dijadikan makanan. Serasah merupakan sisa-sia tumbuhan yang mengandung zat organik tanah dan sebagai bahan makanan bagi semut (Meilina et al., 2017).

\section{Kesimpulan}

Berdasarkan hasil penelitian dapat disimpulkan semut yang ditemukan terdiri dari 4 Subfamili dan 7 Genus semut. Jumlah keseluruhan genus semut yang didapat yaitu 1.861 individu. Indeks keanekaragaman pada seluruh jalur penelitian memiliki nilai $\bar{H}=$ 1,44. Indeks keseluruhan kekayaan jenis memiliki nilai $\mathrm{DMg}=5,58$ menunjukan kekayaan jenis semut masuk kategori tinggi pada skala kategori $\mathrm{DMg}>4$. Indeks kemerataan dengan nilai 0,74 , kemerataan jenis semut tergolong cukup merata.

\section{Saran}

Penelitian mengenai semut perlu dilakukan untuk selanjutnya, tidak hanya keanekaragaman dan jenis-jenis semut tetapi dari kasta semut, bentuk dari sarang semut, simbiosis semut terhadap tumbuhan di sekitar gedung baru Fakultas Kehutanan.

\section{DAFTAR PUSTAKA}

Agussalim, Agus A, Umami N, Budisatria IGS. 2017. Variasi Jenis Tanaman Pakan Lebah Madu Sumber Nektar Dan Polen Berdasarkan Ketinggian Tempat Di Yogyakarta. Buletin Peternakan. 41 (4): 448-460

Evahelda E, Pratama F, Malahayati N, Santosa B. 2017. Sifat Fisik dan Kimia Madu dari Nektar Pohon Karet di Kabupaten Bangka Tengah, Indonesia. AGRITECH, 37(4): 363-368

Federle W, B. Fiala \& U. Maschwitz. 1998.Camponotus(Colobopsis) (Mayr 1861) and Macaranga (Thouars 1806): a specific two-partner ant-plant system from Malaysia,Tropical Zoology, 11: 83-9.

Griffiths M. Hannah, Ashton A. Louise. 2017. Ants are the major agents of resource removal from tropical rainforests. Journal of Animal Ecology 87: 293-300.

Haneda N. F., Yuniar N. 2015. Komunitas Semut (Hymenoptera: Formicidae) Pada Empat Tipe Ekosistem Yang Berbeda Di Desa Bungku Provinsi Jambi. Jurnal Silvikultur Tropika 06(3): 203-209.

Ludwig JA, Reynolds FR. 1988. Statistical Ecology: A Primer of Methods and Computing. John Willey and Sons, New York.

Maftu'ah E, Alwi M, dan Willis M. 2005. Potensi Makrofauna Tanah Sebagai Bioindikator Kualitas Tanah Gambut. Bioscientiae 2(1):1-14. http://bioscientiae.tripod.com. 
Magurran AE. 1983. Ecological Diversity and Its Measurement. University of Oxford.

Magurran AE. 1988. Ecological Diversity and Its Measurement. Princeton University. Press. American

Meilina D, T. R. Setyawati, A. H. Yanti. 2017. Ragam Jenis Semut (Hymenoptera: Formicidae) di Lahan Gambut Alami dan Perkebunan Sawit di Kecamatan Sungai Ambawang Kabupaten Kubu Raya. Jurnal Protobiont 6(3): $68-74$.

Pecarevic M, Danoff-Burg J, Dunn RR. 2010. Biodiversity On BoardwayEnigmatic Diversity of The Societies Of Ants (Formicidae) On The Streets Of New York City. PLos ONE 5 (5). Jurnal Pone, University of Arizona, United States of America.
Rahmawati. 2004. Studi Keanekaragaman Mesofauna Tanah Di Kawasan Hutan Wisata Alam Sibolangit. e-USU Repository.

Riyanto. 2007. Kepadatan, pola, distribusi dan peranan semut pada tanaman di sekitar Tanaman di Sekitar Lingkungan Tempat Tinggal. Jurnal Penelitian Sains: 10(2): 241-253, Dosen Pendidikan Biologi FKIP Unsri.

Wang C, Strazanac J, Butler L.2000. Abundance, Diversity, and Activity of Ants (Hymenoptera: Formicidae) in Oak-dominated Mixed Appalachian Forest With Microbial Pesticides. Enviromental Ecology, Wasington: Smithsonian Institution Press

Wood M. 1995. Environmental Soil Biology 2nd Edition. London (GB): Blackie Academic and Professional. 